\title{
Síndrome de hiperinfección por Strongyloides stercoralis que se presenta como falla ventilatoria aguda en una paciente con inmunosupresión por VIH: reporte de caso
}

\author{
Hyperinfection syndrome due to Strongyloides \\ stercoralis presenting as acute respiratory \\ failure in a patient with immunosuppression \\ due to HIV: a case report
}

\author{
Aníbal Cortés-Bravo ${ }^{1}$, Óscar Saenz-Morales ${ }^{2}$, Francisco González-Acosta ${ }^{3}$, Paola Bonilla-

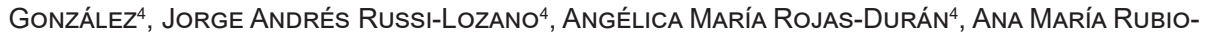 \\ VILlamizaR $^{4}$, Maricely Esperanza Reina-ReVelo ${ }^{4}$, Paulina OJeda-León ${ }^{5}$
}

\section{Resumen}

La estrongiloidosis es una infección causada por el parásito Strongyloides stercoralis $(S$. stercoralis), la cual puede presentar una alta morbimortalidad en los pacientes inmunocomprometidos, con desnutrición grave y coinfección con el virus de la inmunodeficiencia humana $(\mathrm{VIH})$. Se puede desarrollar una hiperinfección, dado que el parásito tiene el potencial de producir una autoinfección interna. Se presenta el caso de una infección pulmonar por $S$. stercoralis que progresó a una falla respiratoria y requirió soporte ventilatorio y hemodinámico en una unidad de cuidados intensivos (UCI), por lo que se le suministró tratamiento estándar combinado de ivermectina. Posteriormente, el paciente falleció.

En este caso clínico se presentan y se discuten algunos aspectos de un caso de hiperinfección por S. stercoralis (HSS). Esta se ha descrito en pacientes con inmunosupresión por trasplante, desnutrición, alcoholismo e infección por VIH. Particularmente, la administración de corticoides sistémicos precipita la muda de larvas rabditoides intestinales a filariformes invasoras. Así, en los pacientes infectados crónicamente, quienes presentan una disminución drástica de la inmunidad celular, el parásito se multiplica en abundancia y se disemina por los pulmones, el hígado, el encéfalo y otros órganos; este se denomina síndrome de HSS, el cual tiene una elevada mortalidad. La posibilidad de que su incidencia aumente por el movimiento migratorio poblacional y en determinadas regiones debe alertarnos de la posible presencia de HSS, sobre todo en pacientes inmunodeprimidos. En los pacientes de riesgo, frente a la sospecha de esta parasitosis, debería recurrirse a métodos complementarios para la detección de larvas, como el coprocultivo, lo que nos permitiría actuar de forma temprana, evitar su diseminación y cambiar el pronóstico de estos pacientes.

Palabras clave: Strongyloides stercoralis, síndrome de distrés respiratorio agudo, síndrome de hiperinfección.

\begin{abstract}
The strongyloidiasis is an infection caused by a parasite known as Strongyloides stercoralis, this infection has a high morbidity and mortality in immunocompromised patients, with serious malnutrition and coinfection with the HIV virus. A hyper infection can be developed, given that the parasite has potential to develop an internal autoinfection. A case of pulmonary infection is present due to $S$. stercoralis that progressed to respiratory failure and required ventilatory and hemodynamic support in the intensive care unit, providing the standard combined treatment of ivermectin with a subsequent death of the patient.
\end{abstract}

In this clinical case, some aspects are presented and discussed related to a case of hyperinfection by Strongyloides stercoralis (HSS). It has been described in patients with immunosuppression due to a transplant, malnutrition, alcoholism and with infection by the human
${ }^{1}$ Médico residente en Medicina Interna, Universidad el Bosque, Hospital Santa Clara.

${ }^{2}$ Médico neumólogo, servicio de urgencias, Hospital Santa Clara. Docente, Universidad El Bosque.

${ }^{3}$ Médico farmacólogo, bioeticista, servicio de urgencias, Hospital Santa Clara Profesor titular, Universidad El Bosque.

${ }^{4}$ Médico internista, servicio de urgencias, Hospital Santa Clara. Docente, Universidad El Bosque.

${ }^{5}$ Médico patólogo, Universidad Nacional de Colombia.

Autor de correspondencia

Oscar Sáenz-Morales.

Correo electrónico: oasm16790@gmail.com

Recibido: 03/06/2020

Aceptado:04/06/2020 
immunodeficiency virus (HIV). Particularly, the administration of systemic corticosteroids causes the change of intestinal rabditoid larvae to invasive filariform. Thereby, in chronically infected patients, who have a drastic decrease in cellular immunity, the parasite multiplies abundantly and spreads through the lungs, liver, brain, and other organs; it is the so-called HSS syndrome, which has a high mortality rate. The possibility that its incidence may increase due to population migration and in certain regions, should alert us to the possibility of HSS, especially in immunosuppressed patients. In front of the suspicion of this parasitosis, in patients at risk should resort to complementary methods for the detection of larvae, such as coprocultivo, which would allow us to act early, prevent its spread and change the unfortunate prognosis of these patients.

Keywords: Strongyloides stercoralis; Acute Respiratory Distress Syndrome; Hyperinfection Syndrome.

\section{Descripción del caso}

Paciente femenina de 47 años edad, quien consulta por un cuadro clínico de 1 mes de evolución consistente con disfagia para sólidos y líquidos. De manera previa tuvo una valoración por el servicio de otorrinolaringología, donde se documentó un cuadro de laringotraqueitis de posible etiología bacteriana frente a la fúngica. Existe sospecha de histoplasma.

Entre los antecedentes se encuentran la infección por VIH desde el 2017 y neumocistosis, adherente al tratamiento médico, que está en manejo con azitromicina, trimetoprima/sulfametoxazol y tratamiento antirretroviral (TARV): dolutegravir (DTG)/fortovase $(\mathrm{FTV})+$ tenofovir (TDF). La paciente no refiere alergias ni exposición a tóxicos.

Se hospitaliza por el servicio de infectología y se le indica un tratamiento con azitromicina más trimetoprima/sulfametoxazol. De manera conjunta al cuadro clínico, presenta un cuadro de 7 días de evolución consistente con disnea progresiva asociada a tos abundante sin fiebre y deterioro respiratorio, por lo que se decide que debe ingresar a la unidad de reanimación en urgencias, con un diagnóstico presuntivo de compromiso pulmonar en un paciente con VIH.

Ingresa consciente a reanimación, con signos de dificultad respiratoria, afebril, con saturación arterial de oxígeno $\left(\mathrm{SatO}_{2}\right)$ por pulsioximetría de $87 \%$, con soporte de oxígeno $\left(\mathrm{FiO}_{2} 50 \%\right)$ e hipotensa $(70 / 40 \mathrm{~mm}$ $\mathrm{Hg}$ ). Su frecuencia cardíaca (FC) es de 116 latidos por minuto (lpm), presenta taquipnea con 26 respiraciones por minuto (rpm), disfonía, con sequedad de mucosa oral y palidez mucocutánea generalizada. Se evidencian estertores finos pulmonares bibasales, y el abdomen no tiene signos de irritación peritoneal. No pre- senta signos de sobrecarga de volumen representada por ingurgitación yugular; sin embargo, presenta edema de los miembros inferiores. Su estado neurológico no presenta deterioro. Se le toman exámenes paraclíni$\cos$ (Tabla 1).

Tabla 1. Paraclínicos

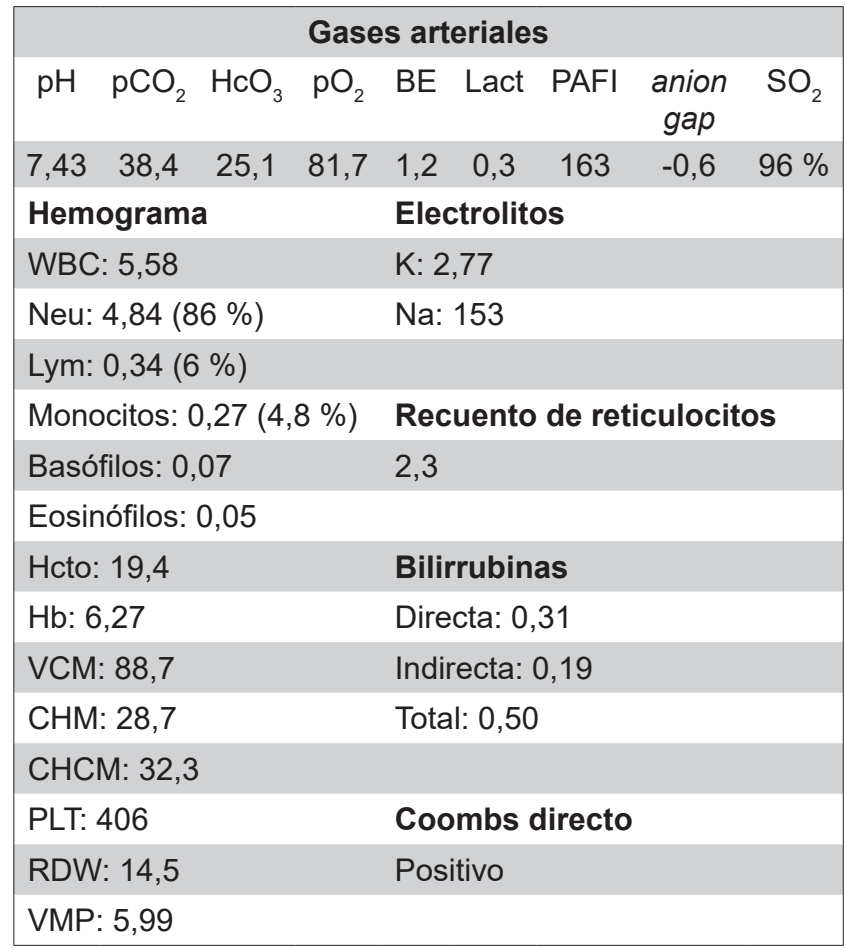

BE: exceso de base; CHCM: concentración de hemoglobina corpuscular media; CHM: hemoglobina corpuscular media; $\mathrm{Hb}$ : hemoglobina; Hcto: hematocrito; $\mathrm{HCO}_{3}$ : bicarbonato; $\mathrm{K}$ : potasio; Lact: lactato; Lym: linfocitos; Na: sodio; Neu: neutrófilos; PAFI: relación entre la presión arterial de oxígeno y la fracción inspirada de oxígeno $\left(\mathrm{PaO}_{2} / \mathrm{FIO}_{2}\right) ; \mathrm{pCO}_{2}$ : presión parcial de dióxido de carbono; PLT: plaquetas; $\mathrm{pO}_{2}$ : presión parcial de oxígeno; $\mathrm{SO}_{2}$ : dióxido de azufre; $\mathrm{RDW}$ : amplitud de distribución eritrocitaria; VCM: volumen corpuscular medio; VMP: volumen plaquetario medio; WBC: recuento de glóbulos blancos. 
Se realizaron una radiografía (Figura 1) y una tomografía de tórax (Figura 2), las cuales evidencian hipertensión pulmonar con parches de consolidación en los 4 cuadrantes, de predominio en ambos ápices, un engrosamiento de los septos interlobulillares con áreas de vidrio esmerilado y opacidades nodulares inespecíficas.

La paciente evolucionó con dificultad respiratoria progresiva, por lo que requirió finalmente ventilación mecánica invasiva con necesidad de parámetros ventilatorios altos; además, requirió soporte vasoactivo con norepinefrina por una hipotensión arterial persistente. Ante la sospecha de una neumonía bacteriana se inició una cobertura antibacteriana de amplio espectro, y ante la sospecha de un compromiso pulmonar con coinfecciones pulmonares se solicitó una broncoscopia, en la que se observaron larvas de S. stercoralis (Figura 3). Por esta razón, se le administró una dosis de ivermectina $(200 \mu \mathrm{g} / \mathrm{kg})$. También se descartó una tuberculosis pulmonar con baciloscopias seriadas negativas y en la fibrobroncoscopia, así como la presencia de otros gérmenes asociados.

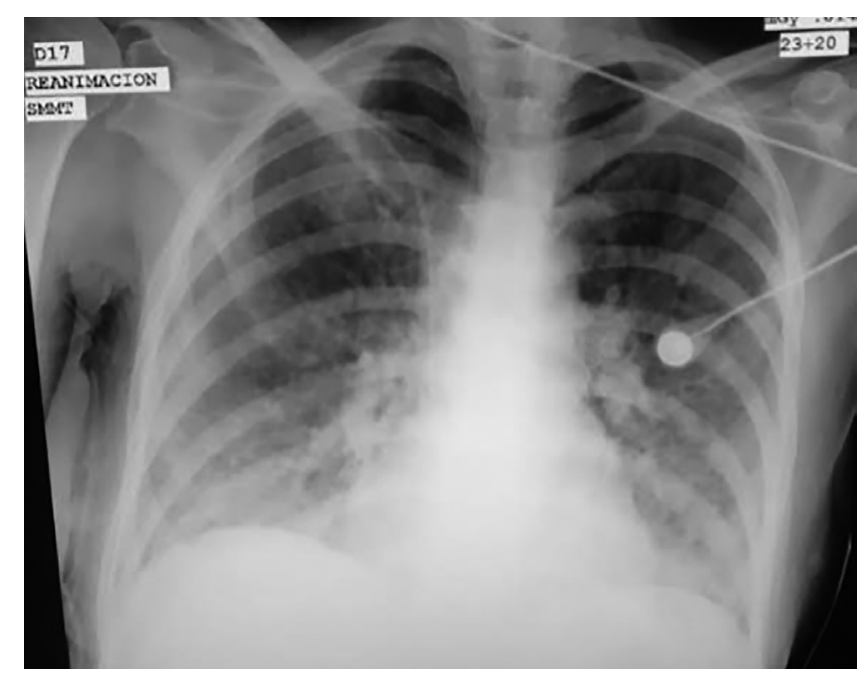

Figura 1. Imágenes diagnósticas de la radiografía de tórax. Proceso infiltrativo extenso intersticial difuso bilateral, senos pleurales libres, silueta cardiovascular y mediastino sin alteraciones; catéter venoso subclavio derecho con su extremidad en la aurícula derecha, estructuras óseas y partes blandas normales. Elementos de monitorización.

Durante 9 días persiste la dependencia de la ventilación mecánica y de soporte inotrópico, sin una respuesta adecuada, por lo cual fallece.

\section{Discusión}

S. stercoralis es un nematodo endémico presente en las regiones tropicales húmedas, que incluyen África, el sudeste asiático y América Latina. También es endémico en el sureste de Estados Unidos y el sur de Europa, aunque en estas dos últimas regiones la mayoría de los casos son importados (1).

El médico francés Louis Normand lo identificó por primera vez en julio de 1876, en el Hospital Naval Mandrier de Tolón, Francia, al examinar la materia fecal de soldados que presentaban diarrea severa, quienes habían regresado del servicio militar en la Cochinchina (hoy Vietnam). En el examen se detectaron larvas móviles de un gusano hasta entonces no identificado, al cual denominó Anguillula stercoralis (2).

El género Strongyloides incluye más de cincuenta especies, de las cuales solo dos de ellas son patógenas para el hombre: S. stercoralis y S. fuelleborni. Para la primera, el hombre es huésped exclusivo, mientras que, para la segunda, los principales huéspedes son los primates africanos; sin embargo, se han documentado infecciones en seres humanos en África y Papúa Nueva Guinea. Strongyloides presenta varios estados: la hembra adulta, larva rabditiforme, larva filariforme, y adultos hembras y machos de vida libre (2).

La infección se adquiere por el contacto con suelo o agua infectadas por larvas filariformes, las cuales penetran la piel. Una vez en el interior del huésped, el torrente sanguíneo lleva las larvas hasta los pulmones, donde atraviesan los capilares pulmonares y salen a los alvéolos; desde allí migran a la tráquea y la faringe, donde son deglutidas y, al llegar al duodeno, la hembra deposita los huevos, que dan lugar a larvas rabditiformes que no son infecciosas para el hombre. Algunas de estas larvas pueden transformarse en larvas filariformes en el propio intestino y autoinfectar al huésped a través de la mucosa colorrectal, lo que perpetúa la infección durante muchos años (2).

Alrededor de 100 millones de personas en el mundo se encuentran infestadas con $S$. stercoralis. En Colombia no se tienen datos actualizados de su prevalencia; la última encuesta nacional de prevalencia de parásitos intestinales fue realizada entre 1977-1980, en la cual 

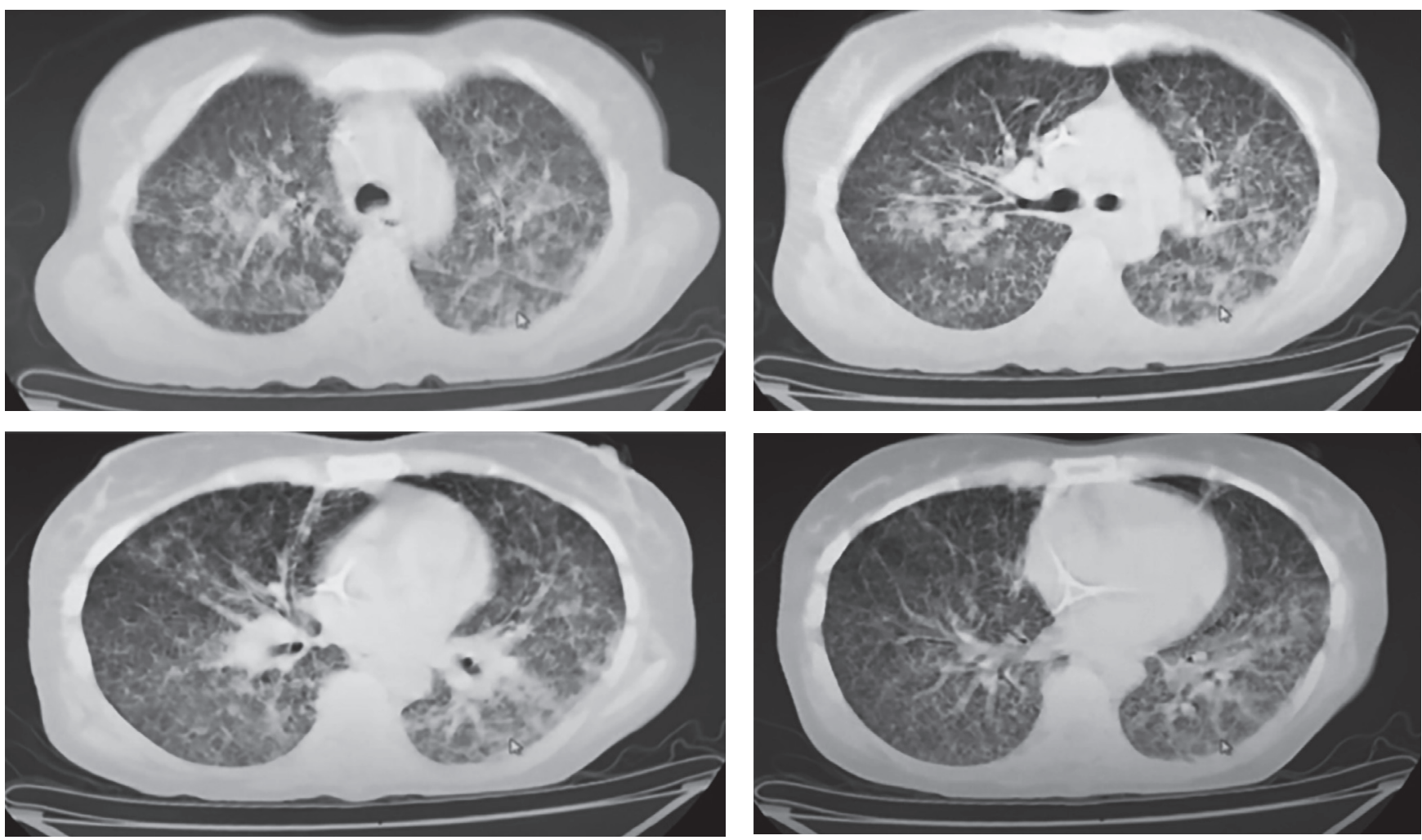

Figura 2. Tomografía de tórax. Tráquea, Carina, bronquios fuentes y lobares de aspecto normal, aorta de calibre normal, que no se puede valorar adecuadamente debido a la ausencia de medio de contraste intravenoso, al igual que la arteria pulmonar; corazón con cuatro cámaras sin alteraciones intraluminales; engrosamiento pleural posterior en el hemitórax izquierdo; catéter venoso subclavio derecho con su extremidad en la aurícula derecha. A nivel pulmonar se observa un extenso proceso infiltrativo intersticial, con ocupación alveolar en la región apical derecha, sin la presencia de nódulos ni masas pulmonares; patrones de vascularización pulmonar y bronquial normales. Estructurales óseas y partes blandas normales. Se concluye la presencia de una enfermedad pulmonar intersticial difusa de etiología por determinar.
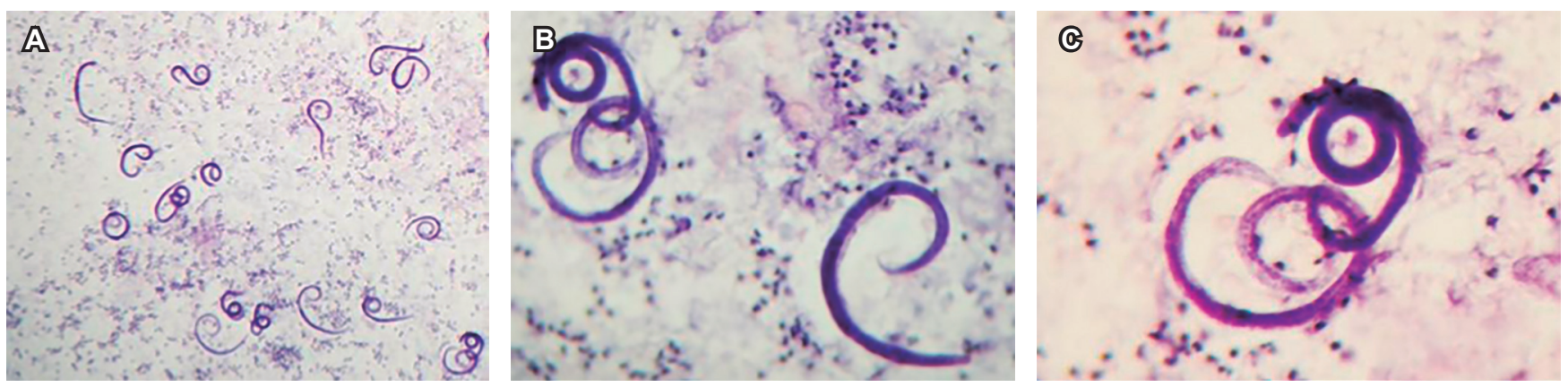

Figura 3. Citología de lavado broncoalveolar. A. H-E 10X lavado broncoalveolar que muestra abundantes larvas de estrongiloides en medio de infiltrado inflamatorio de neutrófilos. B. H-E 40X lavado broncoalveolar que muestra larvas de estrongiloides en medio de infiltrado inflamatorio de neutrófilos. C. H-E 40X lavado broncoalveolar que muestra larvas de estrongiloides en medio de infiltrado inflamatorio de neutrófilos. 
se reportó la presencia de este parásito en 1,3\% de la población escolar y en los adolescentes (3). Schär y colaboradores, en 2013, con base en los resultados revisados de estudios realizados en la comunidad, reportaron una prevalencia del 56,2\% en Colombia (4).

La infección por este parásito ha ganado importancia en los últimos años por varias razones: primero, entre todos los nemátodos que parasitan al hombre es el único capaz de reproducirse dentro del ser humano y permanecer en forma indefinida; segundo, la inmunosupresión permite que se presenten estados graves de la infección, con tasas de mortalidad que alcanzan $80 \%$; tercero, el incremento de las migraciones a países desarrollados del explican el incremento en el número de casos importados en los últimos años en tales regiones; y cuarto, los tratamientos disponibles pueden disminuir la población de parásitos, pero no siempre es posible su erradicación (2).

La hiperinfección es la forma más grave y se debe a la autoinfección masiva y diseminada de larvas filariformes a los pulmones, el hígado, el corazón, el sistema nervioso central y las glándulas endocrinas, lo que induce una inflamación que puede provocar una disfunción multiorgánica e incluso un choque séptico asociado hasta en un $65 \%$ con complicaciones infecciosas secundarias a bacterias intestinales (1).

El síndrome de autoinfección acelerada es una hiperinfección que resulta de una alteración en el estado inmune. La distinción entre autoinfección e hiperinfección no está estrictamente definida, pero el síndrome de hiperinfección implica la presencia de signos y síntomas atribuibles a una mayor migración larval. Este se ha descrito hasta 64 años después de que un individuo haya abandonado un área endémica. Si no se trata, la tasa de mortalidad de la enfermedad diseminada se aproxima al $100 \%$

El diagnóstico de la infección por S. stercoralis se realiza por pruebas de laboratorio que permitan la detección de las larvas rabditiformes, idealmente en muestras de materia fecal, aunque también pueden utilizarse muestras de esputo, líquido cefalorraquídeo u orina. En el hemograma cabría esperar eosinofilia, lo que orientaría hacia la sospecha de una infección por parásitos, pero cuando ya se ha desarrollado una hiperinfección no hay eosinofilia y el recuento de leucocitos es variable, lo que podría ser normal como en el caso anteriormente expuesto.

Para realizar el diagnóstico existen diferentes técnicas, entre ellas el coprológico directo, el coprológico por concentración y el aislamiento en placa de agar; sin embargo, los métodos parasitológicos son de baja sensibilidad debido a la eliminación escasa e irregular de larvas en heces.

Es bien conocido que el coprológico directo y el coprológico por concentración con formoléter muestran una baja sensibilidad en el diagnóstico de la estrongiloidiasis ( $0 \%$ al $52 \%$ y $13 \%$ al $55 \%$, respectivamente), mientras que el aislamiento en placa de agar ha mostrado una sensibilidad entre el $78 \%$ y $100 \%$.

En la actualidad se encuentran disponibles algunas pruebas serológicas y moleculares para detectar la presencia de $S$. stercoralis: la prueba ELISA, la inmunofluorescencia directa con anticuerpos monoclonales y los sistemas de inmunoprecipitación por luciferasa. La prueba ELISA es de utilidad controvertida en las zonas endémicas de geohelmintos. Por su parte, en el estudio liderado por Boscolo y colaboradores (5) con inmunofluorescencia directa con anticuerpos monoclonales se determinó la sensibilidad y especificidad contra el parásito, y se encontraron títulos de inmunoglobulina $\mathrm{G}$ $(\mathrm{IgG}) \geq 1: 20$, con una sensibilidad del $97 \%$ y una especificidad del $98 \%$; para el diagnóstico, esta es una técnica compleja en relación a otros métodos serológicos y requiere de personal técnico bien entrenado para la preparación del antígeno y la lectura de las preparaciones. Por último, los sistemas de inmunoprecipitación por luciferasa (LIPS, por su sigla en inglés) con resultados superiores en comparación con otros inmunoensayos sensibilidad (97\%) y mejor especificidad (100\%), con la ventaja de que no presenta reacciones cruzadas y se puede realizar en un tiempo menor ( $<2,5$ horas). Además, los autores sugieren que la técnica LIPS permite evidenciar la reversión a la seronegativización del paciente luego del tratamiento. Sin embargo, y pese a sus ventajas, esta es una prueba que no se encuentra disponible en los laboratorios clínicos de nuestro medio para el diagnóstico de rutina. La reacción en cadena 
de polimerasa (PCR) y los estudios de genómica fundamental, proteómica y metabolómica ofrecen bases aplicadas para la prevención y el tratamiento.

El principal factor de riesgo para presentar una hiperinfección es la inmunodepresión celular secundaria al tratamiento con glucocorticoides y otros medicamentos inmunosupresores, la infección retroviral, como la infección por el virus linfotrópico de células T humanas tipo 1 (HTLV-1) y el VIH; otras condiciones predisponentes reconocidas para la infección incluyen vivir en una región endémica, malnutrición crónica, tumores malignos, trasplante de órganos, diabetes mellitus, enfermedad pulmonar obstructiva crónica (EPOC), alcoholismo, insuficiencia renal crónica y leche materna de una madre infectada. La inmunidad humoral también parece importante en el control de esta parasitosis al aumentar el riesgo de hiperinfección en la hipogammaglobulinemia.

\section{Conclusiones}

$S$. stercoralis es un geohelminto de importancia médica en Colombia y el mundo, que afecta a diferentes grupos etarios, tanto a hospederos inmunocompetentes como inmunocomprometidos, especialmente a aquellos con infecciones retrovirales como el HTLV-1 y el VIH.

En la actualidad no se dispone de datos exactos sobre la prevalencia de esta parasitosis debido a las diversas dificultades que se presentan respecto a su diagnóstico, por ello es importante implementar la técnica de detección mejor descrita en los laboratorios clínicos para la estrongiloidiasis, así como el aislamiento en placa de agar, con 5-7 repeticiones en días consecutivos y dos agares por cada paciente.
Desde el punto de vista terapéutico, la ivermectina, el tiabendazol y el albendazol son medicamentos efectivos para el tratamiento de la infección. La ivermectina es el medicamento de elección; ha mostrado ser superior con respecto al tiabendazol en la erradicación de la infección y es mejor tolerada. Además, se ha usado con éxito en la hiperinfección, incluso en aquellos que no respondieron al tiabendazol. El mejor esquema de tratamiento no está definido; sin embargo, se considera que, en casos graves, la combinación de ambos medicamentos puede ser la mejor opción $(6,7)$.

\section{Referencias}

1. Montes M, Sawhney C, Barros N. Strongyloides stercoralis: there but not seen. Curr Opin Infect Dis. 2010 Oct;23(5):5004. doi: 10.1097/QCO.0b013e32833df718

2. Arango J. Strongyloides stercoralis. Colombia Médica. 2009;29(1):32-42.

3. Corredor A, Arciniegas E, Hernández CA, Caceres E, Castaño de Romero L, Estupiñan D, et al. Parasitismo intestinal. En: Corredor A, Arciniegas E, Hernández CA, eds. Parasitismo intestinal. Ministerio de Salud, Instituto Nacional de Salud. Bogotá D.C.: Instituto Nacional de Salud; 2000. p. 67-68.

4. Schär F, Trostdorf U, Giardina F, Khieu V, Muth S, Marti H, Vounatsou P, Odermatt P. Strongyloides stercoralis: Global Distribution and Risk Factors. PLoS Negl Trop Dis. 2013;7(7):e2288. doi: 10.1371/journal.pntd.0002288

5. Boscolo M, Bisoffi Z. Dissemination: the fatal risk for a missed diagnosis of Strongyloides stercoralis infection. J Infect. 2007;55(3):284-5. doi: 10.1016/j.jinf.2007.01.009.

6. Buonfrate D, Requena-Mendez A, Angheben A, Muñoz J, Gobbi F, Van Den Ende J, Bisoffi Z. Severe strongyloidiasis: a systematic review of case reports. BMC Infect Dis. 2013 Feb 8;13:78. doi: 10.1186/1471-2334-13-78

7. Levenhagen MA, Costa-Cruz JM. Update on immunologic and molecular diagnosis of human strongyloidiasis. Acta Trop. 2014 Jul;135:33-43. doi: 10.1016/j.actatropica.2014.03.015 